\title{
Características físico-químicas de batata em função de doses e fracionamentos de nitrogênio e potássio
}

\section{Physico-chemical characteristics of potato tubers in function of the doses and time of nitrogen and potassium application}

\author{
Adriana Dias Cardoso ${ }^{1}$, Marco Antônio Rezende Alvarenga², Fabrício Vieira Dutra ${ }^{1, *}$, \\ Thiago Lima Melo ${ }^{1}$ e Anselmo Eloy Silveira Viana ${ }^{1}$
}

\author{
${ }_{1}^{1}$ Departamento de Fitotecnia e Zootecnia - Universidade Estadual do Sudoeste da Bahia, Estrada do Bem Querer, Km 4, CP 95, CEP 45031-900, Vitória da Conquista, Bahia, Brasil \\ 2 Universidade Federal de Lavras, Lavras, Minas Gerais, Brasil \\ ( ${ }^{\star}$ E-mail: fabriciovieira94@hotmail.com) \\ http://dx.doi.org/10.19084/RCA17015
}

Recebido/received: 2017.01 .24

Recebido em versão revista/received in revised form: 2017.03 .16

Aceite/accepted: 2017.04.18

\section{R E S U M O}

O objetivo deste trabalho foi caracterizar química e fisicamente batatas cultivadas sob diferentes doses e fracionamentos de nitrogênio e potássio. Foram utilizadas três doses de N e K (75\% da dose recomendada; dose recomendada de acordo com a análise do solo e $125 \%$ da dose recomendada) e cinco épocas de aplicação (100\% no plantio; 1/3 no plantio e 2/3 na tuberização; $50 \%$ no plantio e $50 \%$ na tuberização; $1 / 3$ no plantio, $1 / 3$ na tuberização e $1 / 325$ dias após a tuberização; $1 / 4$ no plantio, $1 / 4$ na tuberização, $1 / 425$ dias após a tuberização e $1 / 450$ dias após a tuberização). O delineamento experimental utilizado foi o de blocos ao acaso, em esquema fatorial $5 \times 3$, com quatro repetições. Foram utilizados tubérculos da cultivar Ágata, uniformemente brotados. As características avaliadas foram: firmeza, $\mathrm{pH}$, sólidos solúveis, acidez total titulável, açúcares redutores e açúcares totais. Os dados foram submetidos à análise de variância e teste Tukey, a $5 \%$ de probabilidade. Apenas o uso do fracionamento de $\mathrm{N}$ e K influenciou no teor de açúcares redutores.

Palavras-chave: Solanum tuberosum L., Adubação, Pós-colheita, Açúcar.

\begin{abstract}
A B S T R A C T
The present work was carried out aiming to evaluate chemical and physical characteristics of potato tubers in function of the doses and time of nitrogen and potassium application. Three doses of $\mathrm{N}$ and $\mathrm{K}$ ( $75 \%$ of the recommended dose; recommended dose according to soil analysis; $125 \%$ of the recommended dose; recommended dose according to soil analysis) and five application times were used (100\% upon planting; $1 / 3$ upon planting and $2 / 3$ upon tuberization; $50 \%$ upon planting and $50 \%$ upon tuberization; $1 / 3$ upon planting, $1 / 3$ upon tuberization and $1 / 325$ days after tuberization; $1 / 4$ upon planting, $1 / 4$ upon tuberization, $1 / 425$ days after tuberization and $1 / 450$ days after tuberization) and. The experimental outline was the factorial one $(3 \times 5)$, with plots arranged in randomized blocks with four repetitions. Tubers from the Agata cultivar, uniformly budded. Firmness was assessed, as well as soluble solids, total titulable acidity, total soluble sugars and reducing sugars. The data were submitted to the variance analysis and Tukey teste at $5 \%$ of probability. Only the application time and the doses of $\mathrm{N}$ and $\mathrm{K}$ did promote significant responses in the content of reducing sugars in the tubers potato Agata.
\end{abstract}

Keyworks: Solanum tuberosum L., Fertilization, Postharvest, Sugars. 


\section{INTRODUÇÃO}

A cultura da batata (Solanum tuberosum L.) desempenha importante papel na alimentação humana, constituindo uma das principais fontes de carboidrato. Atualmente, é o quarto alimento mais consumido no mundo, depois do trigo, arroz e milho. Sua produção mundial foi de 385,07 milhões de toneladas no ano de 2014 (FAO, 2017).

Das cultivares de batata mais utilizadas no Brasil destaca-se Ágata que é a mais plantada no país e mais aceita no mercado para comercialização do tubérculo in natura. Entretanto, possui baixo conteúdo de massa seca, maior conteúdo de açúcares, etc. características essas adequadas para o mercado fresco, com indicação para o preparo de massas e pratos assados em que é essencial a manutenção de sua forma (Fernandes et al., 2010).

Apesar de sua importância e das pesquisas com a cultura, existem poucos estudos relacionando adubação mineral e qualidade dos tubérculos de batata. Características pós-colheita fazem a diferença na aceitação do produto no mercado com reflexos econômicos.

De acordo com Evangelista et al. (2011) e Fernandes et al. (2015), as características físico-químicas dos tubérculos de batata podem ser afetadas por vários fatores, entre eles: cultivar, disponibilidade de nutrientes, etc.

Assim, a adubação pode ser considerada como um dos principais fatores que interferem na qualidade da batata, tornando-se necessário estabelecer aplicações equilibradas dos nutrientes para proporcionar aumento na qualidade do seu produto.

Além disso, esta cultura responde bem à adição de nutrientes no solo (Fernandes et al., 2011; Luz et al., 2013) e dentre os nutrientes absorvidos pela planta, o nitrogênio é um determinante na produtividade e qualidade de tubérculo e sua falta ou excesso gera uma série de problemas (Baggio et al., 2009). $\mathrm{O}$ excesso de nitrogênio pode estimular maior crescimento da parte aérea, reduzir a massa seca e o amido nos tubérculos, os quais poderão favorecer a maior absorção de gordura após o processo de gordura, retardar a maturação e com isto prolongar a duração do período vegetativo. Pode causar também aumento dos açúcares redutores, favorecendo o escurecimento após o processo de fritura (Braun et al., 2010).

Para Zebarth etal. (2009), as boas práticas de manejo do fertilizante nitrogenado são importantes para otimizar a produtividade e a qualidade dos tubérculos.

O potássio é o nutriente mais extraído pela batata (Fernandes, 2010). Melhora a qualidade dos tubérculos (tamanho, peso, coloração, sabor e propriedades culinárias), acelerando o fluxo e a translocação dos fotoassimilados das folhas para os tubérculos. Entretanto, doses excessivas de potássio proporcionam menor produção de fotoassimilados, comprometendo a produtividade da cultura da batata (Pereira et al., 2014).

Segundo Silva et al. (2014), as tabelas de recomendação de adubação não consideram as características específicas de cada cultivar. Para obter tubérculos de batata com maior qualidade após a colheita, segundo Fernandes et al. (2011), é importante fazer o manejo da adubação de acordo com a cultivar utilizada.

Diante disso, torna-se necessária avaliação destes fatores em locais de cultivo ainda não estudados, como exemplo de Mucugê que detém maior produção de batata no estado da Bahia (IBGE, 2017), onde apresentam características climáticas desejáveis para o desenvolvimento deste tubérculo. O objetivo do presente trabalho foi avaliar as características físico-químicas da batata em função da época e fracionamento da aplicação de N e K na adubação.

\section{MATERIAL E MÉTODOS}

O experimento foi instalado na Fazenda Progresso II, localizada no distrito de Cascavel, no município de Mucugê, região centro sul da Bahia, a $13^{\circ} 00^{\prime} 19^{\prime \prime}$ Latitude Sul e $41^{\circ} 2215^{\prime \prime}$ Longitude Oeste de Greenwich, com altitude média de $984 \mathrm{~m}$.

O solo foi classificado em Latossolo amarelo, com topografia plana, o qual apresentou os seguintes resultados de análise química para a camada de 0-0.20 m de profundidade (após a calagem): $\mathrm{pH}$ 
em $\mathrm{H}_{2} \mathrm{O}(1: 2,5)=5,2 ; \mathrm{P}\left(\mathrm{mg} \mathrm{dm}^{-3}\right)=48 ; \mathrm{K}^{+}, \mathrm{Al}^{3+}, \mathrm{Ca}^{2+}$, $\mathrm{Mg}^{2+}, \mathrm{H}^{+}+\mathrm{Al}^{3+}$, S.B., CTC efetiva e CTC a pH 7,0 $\left(\mathrm{cmolc} \mathrm{dm}^{-3}\right)=0,18 ; 0,3 ; 1,0 ; 1,5 ; 1,7 ; 2,7 ; 3,0$ e 4,4, respectivamente; $\mathrm{m}(\%)=10 ; \mathrm{V}(\%)=61 \% ; \mathrm{M} . \mathrm{O}\left(\mathrm{g} \mathrm{dm}^{-3}\right)=0$; $\mathrm{Cu}^{2+}, \mathrm{Mn}^{2+}, \mathrm{Zn}^{2+}$ e $\left.\mathrm{Fe}^{2+}(\mathrm{mg} \mathrm{dm})^{3}\right)=2,60 ; 1,40 ; 2,70$ e 24,00 , respectivamente.

O preparo do solo foi feito de acordo com o recomendado para a cultura da batata. A adubação foi feita, manualmente, no sulco de plantio obedecendo-se aos tratamentos. Utilizou-se o adubo 4-14-8 e o superfosfato simples na primeira aplicação para todos os tratamentos.

Foram utilizados tubérculos-semente da cultivar Ágata uniformemente brotados. O plantio foi realizado, manualmente, utilizando o espaçamento $0,8 \times 0,3 \mathrm{~m}$.

O delineamento experimental utilizado foi o de blocos casualizados, em esquema fatorial $3 \times 5$, totalizando 15 tratamentos, com quatro repetições. Os tratamentos foram constituídos pelo parcelamento em três vezes das dosagens de $\mathrm{N}$ e K recomendadas pela análise de solo, sendo cada uma dessas dosagens avaliadas em cinco épocas de aplicação, conforme descritos a seguir: A) $75 \%$ da dose recomendada (105 kg ha-1 de N e $210 \mathrm{~kg} \mathrm{ha}^{-1}$ de $\mathrm{K})$; B) dose recomendada de acordo com a análise do solo (140 kg ha-1 de N e $280 \mathrm{~kg} \mathrm{ha}^{-1}$ de K; e C) $125 \%$ da dose recomendada (175 $\mathrm{kg} \mathrm{ha}^{-1}$ de $\mathrm{N}$ e $350 \mathrm{~kg} \mathrm{ha}^{-1}$ de K). Cada um desses tratamentos foi parcelado em cinco épocas de aplicação: 1) $100 \%$ no plantio; 2) $1 / 3$ no plantio e $2 / 3$ na tuberização (28 dias após o plantio); 3) 50\% no plantio e $50 \%$ na tuberização; 4) $1 / 3$ no plantio, $1 / 3$ na tuberização e 1/3 25 dias após a tuberização; 5) 1/4 no plantio, $1 / 4$ na tuberização, $1 / 425$ dias após a tuberização e 1/4 50 dias após a tuberização. Nas aplicações dos parcelamentos 2, 3, 4 e 5, utilizou-se uréia e cloreto de potássio.

A parcela experimental foi composta por 42 plantas, cultivadas em seis linhas com sete plantas em cada linha, sendo consideradas seis plantas úteis, em uma área útil de $1,44 \mathrm{~m}^{2}$. Utilizou-se bordadura externa, margeando-se cada parcela do experimento para não haver influência da adubação.

O controle fitossanitário foi feito sempre que necessário por meio de aplicações preventivas e de controle com defensivos. A irrigação foi realizada por meio de um sistema de irrigação por pivô central, visando atender às necessidades hídricas do sistema solo-planta.

Após a colheita foram avaliadas as seguintes características nos tubérculos: a) firmeza, determinada com o auxílio do texturômetro TR, modelo WA68, Italy, com ponteira de $8 \mathrm{~mm}$ de diâmetro. Foram feitas quatro medições por tubérculo, na região equatorial, após a remoção da pequena porção da casca; b) $\mathrm{pH}$, determinada utilizando-se potenciômetro digital Marte, modelo MB-10, São Paulo, segundo a técnica da AOAC (1992); c) sólidos solúveis, determinada por meio de refratometria, em refratômetro ATTO Instruments, WYT-4, Hong Kong, segundo a AOAC (1992); d) Acidez total titulável, determinada por meio da titulação com solução de $\mathrm{NaOH}$ 0,1 $\mathrm{M}$ de acordo com o Instituto Adolfo Lutz (1985); e) açúcares redutores e açúcares totais, foram extraídos pelo método de Lane Eynon, citado na AOAC (1990) e identificados pelo método redutométrico de Somogy-Nelson (Southgate, 1991).

A análise estatística foi realizada utilizando-se o programa Software SISVAR, procedendo-se à análise de variância e, posteriormente, as médias dos tratamentos foram comparadas pelo teste Tukey, a 5\% de probabilidade. Além disso, foi determinada a correlação de Pearson para as características avaliadas.

\section{RESULTADOS E DISCUSSÃO}

Observa-se, no Quadro 1, que as diferentes doses e parcelamentos da adubação nitrogenada e potássica não alteraram a firmeza dos tubérculos in natura da cultivar Ágata. A firmeza da polpa dos tubérculos está diretamente associada com a composição e a estrutura celular, particularmente com as modificações que ocorrem na parede celular ao longo da maturação (Toivonen e Brummell, 2008). Constitui-se em uma das principais características para o consumidor que ao adquirir o produto na forma in natura, tem preferência por aqueles com maior firmeza. Esse atributo também interessa aos processadores na indústria, pois confere maior rendimento na retirada da película e no corte da polpa. 
Quadro 1 - Firmeza (N) em função do fracionamento e das doses de nitrogênio e potássio, em batata cv. Ágata

\begin{tabular}{|c|c|c|c|c|c|c|}
\hline \multirow{2}{*}{ Dose } & \multicolumn{5}{|c|}{ Fracionamento } & \multirow{2}{*}{ Média } \\
\hline & 1 & 2 & 3 & 4 & 5 & \\
\hline $75 \%$ da dose recom. & 74,95 & 73,95 & 76,57 & 74,39 & 72,70 & $74,51 \mathrm{~A}$ \\
\hline Recomendada & 78,51 & 76,42 & 74,74 & 7476 & 73,44 & $75,57 \mathrm{~A}$ \\
\hline $125 \%$ da dose recom & 75,54 & 78,00 & 76,01 & 76,18 & 75,83 & $76,31 \mathrm{~A}$ \\
\hline Média & $76,33 a$ & $76,12 \mathrm{a}$ & $75,77 a$ & $75,11 \mathrm{a}$ & $73,99 a$ & \\
\hline
\end{tabular}

Médias seguidas da mesma letra minúscula nas linhas e maiúsculas nas colunas, não diferem entre si, pelo teste Tukey a 5\% de probabilidade.

Públio (2008), avaliando as características físico-químicas de tubérculos de batata submetidos a fontes (sulfato de potássio e cloreto de potássio) e concentrações de potássio $\left(200 \mathrm{~g}\right.$ sulco ${ }^{-1}$; $400 \mathrm{~g}$ sulco $^{-1} \mathrm{e} 600 \mathrm{~g} \mathrm{sulco}^{-1}$ ) obteve valores médios de firmeza 70,17 a 74,07 $\mathrm{N}$ em batatas da cultivar Ágata, próximos aos obtidos neste trabalho. Entretanto, Fernandes et al. (2010), estudando a qualidade físico-química de tubérculos de cultivares de batata (Agata, Asterix, Atlantic, Markies e Mondial) na safra de inverno em Itaí-SP, encontraram valores médios de firmeza 6,74 $\mathrm{N}$ para a cultivar Ágata, valores inferiores ao encontrado no estudo. Essa variação, provavelmente, pode estar relacionada ao local de cultivo, que a exemplo citado acima Itaí apresenta clima temperado úmido com verão quente e Mucugê com clima temperado úmido com verão temperado.

A acidez total titulável nos tubérculos de batata não diferiram significativamente entre os tratamentos (Quadro 2). Portanto, o parcelamento e a dose da adubação nitrogenada e potássica não contribuíram para o aumento dessa característica.

Fernandes et al. (2010) encontraram variação de acidez titulável total de 0,20\%, 0,17\%, 0,20\% e $0,20 \%$, para as cultivares Ágata, Asterix, Atlantic e Mondial, respectivamente. Furlaneto et al. (2014), estudando a acidez titulável em batatas da cultivar Ágata, sobre diferentes concentrações de adubação

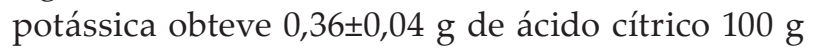
de polpa ${ }^{-1}$. Suchoronczek et al. (2016), avaliando efeito de épocas de colheita e tempo de armazenamento de tubérculos de batata sobre características de qualidade pós-colheita, encontraram valores médios de 0,09 e 0,088\% para Ágata e Atlantic, respectivamente. Isso indica que há variação na acidez total titulável.

A acidez total titulável influencia no sabor e odor dos alimentos e está relacionada com a quantidade de ácidos orgânicos existentes (Cecchi, 2003). De acordo com Chitarra e Chitarra (2005), a acidez titulável está entre os atributos necessários na avaliação pós-colheita de hortaliças, juntamente com perda de massa fresca, cor, firmeza, sólidos solúveis, sólidos solúveis totais, pungência e $\mathrm{pH}$.

Os teores de sólidos solúveis não foram afetados significativamente pelo parcelamento e doses da adubação nitrogenada e potássica (Quadro 3).

Quadro 2 - Acidez total titulável (\%) em função do fracionamento e das doses de nitrogênio e potássio, em batata cv. Ágata

\begin{tabular}{|c|c|c|c|c|c|c|}
\hline \multirow{2}{*}{ Dose } & \multicolumn{5}{|c|}{ Fracionamento } & \multirow{2}{*}{ Média } \\
\hline & 1 & 2 & 3 & 4 & 5 & \\
\hline $75 \%$ da dose recom. & 0,215 & 0,233 & 0,220 & 0,223 & 0,200 & $0,218 \mathrm{~A}$ \\
\hline Recomendada & 0,263 & 0,190 & 0,200 & 0,190 & 0,200 & $0,209 \mathrm{~A}$ \\
\hline $125 \%$ da dose recom & 0,218 & 0,200 & 0,205 & 0,205 & 0,205 & $0,207 \mathrm{~A}$ \\
\hline Média & $0,232 \mathrm{a}$ & $0,208 \mathrm{a}$ & $0,208 \mathrm{a}$ & $0,206 a$ & $0,202 \mathrm{a}$ & \\
\hline
\end{tabular}

Médias seguidas da mesma letra minúscula nas linhas e maiúsculas nas colunas, não diferem entre si, pelo teste Tukey a 5\% de probabilidade. 
Quadro 3 - Sólidos solúveis (\%) em função do fracionamento e das doses de nitrogênio e potássio, em batata cv. Ágata

\begin{tabular}{|c|c|c|c|c|c|c|}
\hline \multirow{2}{*}{ Dose } & \multicolumn{5}{|c|}{ Fracionamento } & \multirow{2}{*}{ Média } \\
\hline & 1 & 2 & 3 & 4 & 5 & \\
\hline $75 \%$ da dose recom. & 4,25 & 4,25 & 4,25 & 4,25 & 4,00 & $4,20 \mathrm{~A}$ \\
\hline Recomendada & 4,25 & 4,25 & 4,25 & 4,25 & 4,25 & $4,25 \mathrm{~A}$ \\
\hline $125 \%$ da dose recom & 4,25 & 4,25 & 4,25 & 4,25 & 4,00 & $4,20 \mathrm{~A}$ \\
\hline Média & $4,25 a$ & $4,25 a$ & $4,25 a$ & $4,25 a$ & $4,08 \mathrm{a}$ & \\
\hline
\end{tabular}

*Médias seguidas da mesma letra minúscula nas linhas e maiúsculas nas colunas, não diferem entre si, pelo teste Tukey a $5 \%$ de probabilidade.

Alguns autores avaliando a característica sólidos solúveis em batata da cultivar Ágata encontraram valores próximos ao obtido neste trabalho. Pinelli et al. (2005) 3,9 e 4,7³rix; Públio (2008) 4,05 a $4,20^{\circ}$ brix; Ferreira (2015) 3,42 a 4,03ํㅏix e Virmond et al. (2014) 4,0 $0^{\circ}$ brix.

Como os sólidos solúveis são constituídos, principalmente, por açúcares (sacarose), o maior teor de graus Brix é indicativo de aumento do conteúdo de sacarose (Virmond et al. 2014). Para Chitarra e Chitarra (2005), o teor de sólidos solúveis totais é utilizado como uma medida indireta do teor de açúcares, podendo variar de $2 \%$ a $25 \%$, a depender da espécie, dos estádios de maturação e do clima, os valores obtidos neste trabalho estão de acordo com este estudo.

O uso do fracionamento e as doses da adubação nitrogenada e potássica não exerceram influência sobre o pH dos tubérculos de batata (Quadro 4). Os valores de $\mathrm{pH}$ obtidos neste experimento indicam que os tubérculos apresentaram boas condições de conservação.

Públio (2008) obteve valores de $\mathrm{pH}$ variando de 5,72 a 5,87 em tubérculos da cultivar Ágata. Virmond et al. (2014) e Fernandes et al. (2010) encontraram o $\mathrm{pH}$ de 6,10, próximo ao obtido neste trabalho, apresentando valores de 6,08 a 6,17. Isso indica que os tubérculos se encontram em bom estado de maturação e conservação, pois os valores de pH ótimos para a ação de enzimas que degradam o amido são menores (Nardin, 2009). Tais valores são semelhantes aos encontrados neste trabalho, podendo-se inferir que o $\mathrm{pH}$ da polpa da batata não sofreu influência da época de aplicação da adubação mineral.

$\mathrm{O}$ pH é uma das características que se destaca na avaliação pós-colheita de tubérculos, por ser um importante indicador para avaliações químicas e biológicas em alimentos, utilizada para o reconhecimento e o controle de processos naturais ou artificiais do produto. $\mathrm{O}$ valor do $\mathrm{pH}$ determina a atividade enzimática, o grau de deterioração do alimento, a variação de textura, o grau de maturação de frutas e hortaliças e a escolha de embalagens e meio de conservação adequados (Chitarra e Chitarra, 2005).

Os principais açúcares encontrados na batata são os redutores (glicose e frutose) e não redutores

Quadro 4 - pH em função do fracionamento e das doses de nitrogênio e potássio, em batata cv. Ágata

\begin{tabular}{lcccccc}
\hline \multirow{2}{*}{ Dose } & \multicolumn{3}{c}{ Fracionamento } & \multicolumn{2}{c}{ Média } \\
\cline { 2 - 6 } & $\mathbf{1}$ & $\mathbf{2}$ & $\mathbf{3}$ & $\mathbf{4}$ & $\mathbf{5}$ & $6,10 \mathrm{~A}$ \\
\hline $75 \%$ da dose recom. & 6,25 & 6,00 & 6,00 & 6,25 & 6,00 & $6,10 \mathrm{~A}$ \\
Recomendada & 6,25 & 6,25 & 6,00 & 6,00 & 6,00 & $6,10 \mathrm{~A}$ \\
125\% da dose recom. & 6,00 & 6,25 & 6,00 & 6,00 & 6,25 & $6,08 \mathrm{a}$ \\
\hline Média & $6,17 \mathrm{a}$ & $6,17 \mathrm{a}$ & $6,00 \mathrm{a}$ & $6,08 \mathrm{a}$ & 6 \\
\hline
\end{tabular}

Médias seguidas da mesma letra minúscula nas linhas e maiúsculas nas colunas, não diferem entre si, pelo teste Tukey a 5\% de probabilidade. 
Quadro 5 - Açúcares redutores (\%) em função do fracionamento e das doses de nitrogênio e potássio, em batata cv. Ágata

\begin{tabular}{|c|c|c|c|c|c|c|}
\hline \multirow{2}{*}{ Dose } & \multicolumn{5}{|c|}{ Fracionamento } & \multirow{2}{*}{ Média } \\
\hline & 1 & 2 & 3 & 4 & 5 & \\
\hline $75 \%$ da dose recom. & 0,088 & 0,030 & 0,050 & 0,058 & 0,060 & $0,057 \mathrm{~A}$ \\
\hline Recomendada & 0,080 & 0,035 & 0,045 & 0,050 & 0,050 & $0,052 \mathrm{~A}$ \\
\hline $125 \%$ da dose recom. & 0,078 & 0,038 & 0,068 & 0,038 & 0,075 & $0,059 \mathrm{~A}$ \\
\hline Média & $0,082 a$ & $0,034 \mathrm{c}$ & $0,054 \mathrm{bc}$ & $0,049 b c$ & $0,062 \mathrm{ab}$ & \\
\hline
\end{tabular}

Médias seguidas da mesma letra minúscula nas linhas e maiúsculas nas colunas, não diferem entre si, pelo teste Tukey a 5\% de probabilidade.

(sacarose), os quais têm valores variados, que oscilam entre épocas de plantio, entre produtores e cultivares (Robles, 2003).

Existem fatores que afetam o teor de açúcares redutores na batata, como grau de maturação do tubérculo na colheita, as condições climáticas e nutricionais em que se desenvolveram as plantas (Zorzella et al., 2003).

Conforme Stark et al. (2003), tubérculos de batatas para serem aceitas para o processamento devem possuir teores de açúcares redutores geralmente abaixo de $0,035 \%$ da massa fresca para processamento na forma de chips e $0,12 \%$ quando processadas na forma de palitos.

De acordo com os resultados obtidos, houve diferença significativa do teor em açúcares redutores com o fracionamento da adubação de $\mathrm{N}$ e K (Quadro 5). As plantas que não foram submetidas a fracionamento desenvolveram tubérculos com maio teor de açúcares redutores em relação às plantas submetidas ao fracionamento 2,3 e 4 .
No mesmo Quadro observa-se que não houve diferença entre as doses aplicadas de $\mathrm{N}$ e K para o teor em açúcares redutores. Estes resultados não estão de acordo com os observados por Quadros et al. (2010) que verificaram em diferentes cultivares de batata uma diminuição do teor de açucares redutores com o aumento da adubação potássica

Não foram verificadas diferenças significativas para o teor em açúcares totais entre os fracionamentos e as doses utilizadas neste trabalho (Quadro 6). Estes resultados não estão de acordo com os obtidos por Braun et al. (2010) que verificaram um efeito de doses de $\mathrm{N}$ sobre o teor de açúcares totais para cultivar Ágata.

Mesquita (2004) obteve valores de açúcares totais variando entre $0,19 \%$ a $0,30 \%$ na cultivar Asterix e 0,19 a 0,20\% para a cultivar Monalisa. Públio (2008), utilizando a fonte sulfato e cloreto de potássio, obtiveram médias de açúcares totais de 0,104 e 0,131\% na cultivar Ágata. Fernandes et al. (2010), avaliando a qualidade físico-química e de fritura de tubérculos de cultivares de batata na safra de inverno, obteve valores médios de $0,20,0,20,0,20$,

Quadro 6 - Açúcares totais (\%) em função do fracionamento e das doses de nitrogênio e potássio, em batata cv. Ágata

\begin{tabular}{lcccccc}
\hline \multirow{2}{*}{ Dose } & \multicolumn{3}{c}{ Fracionamento } & \multicolumn{2}{c}{ Média } \\
\cline { 2 - 6 } & $\mathbf{1}$ & $\mathbf{2}$ & $\mathbf{3}$ & $\mathbf{4}$ & $\mathbf{5}$ & $0,213 \mathrm{~A}$ \\
\hline 75\% da dose recom & 0,223 & 0,128 & 0,365 & 0,138 & 0,213 & $0,154 \mathrm{~A}$ \\
Recomendada & 0,280 & 0,143 & 0,108 & 0,140 & 0,098 & $0,178 \mathrm{~A}$ \\
125\% da dose recom & 0,175 & 0,150 & 0,190 & 0,125 & 0,248 & $0,186 \mathrm{a}$ \\
\hline Média & $0,226 \mathrm{a}$ & $0,140 \mathrm{a}$ & $0,221 \mathrm{a}$ & $0,134 \mathrm{a}$ & \\
\hline
\end{tabular}

*Médias seguidas da mesma letra minúscula nas linhas e maiúsculas nas colunas, não diferem entre si, pelo teste Tukey a $5 \%$ de probabilidade. 
Quadro 7 - Correlações entre as características firmeza (F), sólidos solúveis (SS), acidez total titulável (ATT), pH, açucares redutores (ACR) e açucares totais (ACT), para a cultivar Ágata. 2016

\begin{tabular}{lccccc}
\hline Características & SS & ATT & pH & ACR & ACT \\
\hline F & $-0,01 \mathrm{~ns}$ & $0,12 \mathrm{~ns}$ & $-0,19 \mathrm{~ns}$ & $0,08 \mathrm{~ns}$ & $0,16 \mathrm{~ns}$ \\
SS & & $0,59^{* *}$ & $0,38^{* *}$ & $0,20 \mathrm{~ns}$ & $-0,05 \mathrm{~ns}$ \\
ATT & & $0,15 \mathrm{~ns}$ & $0,33^{* *}$ & $0,09 \mathrm{~ns}$ \\
pH & & & $-0,12 \mathrm{~ns}$ & $-0,21 \mathrm{~ns}$ \\
ACR & & & & $0,27^{*}$ \\
\hline
\end{tabular}

*, ${ }^{\star *}$ Significativo, a $5 \%$ e $1 \%$ de probabilidade, respectivamente, pelo teste $t$; ${ }^{\text {ns }}$ Não significativo.

0,20 e 0,17\% para as cultivares Ágata, Mondial, Markies, Atlantic e Asterix, respectivamente.

Não houve correlação entre firmeza, sólidos solúveis, acidez total titulável, $\mathrm{pH}$, açúcares redutores e totais (Quadro 7). Azzolini et al. (2004) também não encontraram correlação para estas características em goiabas (Quadro 7).

$\mathrm{O}$ pH não se correlacionou com a acidez total titulável. Segundo Martins (2007), não existe correlação direta ou prevista entre o $\mathrm{pH}$ e a acidez total titulável.

Os sólidos solúveis apresentaram correlação positiva com pH e com acidez total titulável.
Houve correlação positiva entre açúcares redutores, acidez total titulável e açúcares totais. Guigou et al. (2011) encontraram correlação forte entre concentração de açúcares totais em equivalentes de glicose e brix do caldo de sorgo sacarino.

\section{CONCLUSÕES}

$\mathrm{O}$ fracionamento e as doses de $\mathrm{N}$ e $\mathrm{K}$ não promoveram variações significativas nas características de firmeza, sólidos solúveis, acidez total titulável, açúcares totais e $\mathrm{pH}$.

Quase todos os fracionamentos de N e K conduziram a diminuição do teor em açúcares redutores dos tubérculos da variedade Ágata.

\section{REFERÊNCIAS BIBLIOGRÁFICAS}

AOAC (1992) - Official methods of analysis of the Association of the Agricultural Chemists. 12. ed. Association of Official Agricultural Chemists, Washington, DC.

AOAC (1990) - Official methods of analysis. 15. ed. Association of Official Agricultural Chemists. Washington, DC.

Azzolini, M.; Jacomino, A.P. \& Bron, I.U. (2004) - Índices para avaliar qualidade pós-colheita de goiabas em diferentes estádios de maturação. Pesquisa Agropecuária Brasileira, vol .39, n. 2, p. 139-145. http://dx.doi. org/10.1590/S0100-204X2004000200006

Baggio, C.A.; Stoetzer A.; Varela, J.R.J.; Müller, M.M.L. \& Kawakami, J. (2009) - Efeito de doses de nitrogênio no crescimento de plantas de batata em Guarapuava. Horticultura Brasileira, vol. 27, p. S3219-S3223.

Braun, H.; Fontes, P.C.R.; Finger, F.L.; Busato, C. \& Cecon, P.R. (2010) - Carboidratos e matéria seca de tubérculos de cultivares de batata influenciados por doses de nitrogênio. Ciência e Agrotecnologia, vol. 34, n. 2, p. 285-293. http://dx.doi.org/10.1590/S1413-70542010000200003

Cecchi, H.M. (2003) - Fundamentos teóricos e práticos em análise de alimentos. 2. ed. Campinas: UNICAMP, 207 p.

Chitarra, M.I.F. \& Chitarra, A.B. (2005) - Pós-colheita de frutas e hortaliças: fisiologia e manuseio. UFLA, Lavras. $785 \mathrm{p}$. 
Evangelista, R.M.; Nardin, I.; Fernandes, A.M. \& Soratto, R.P. (2011) - Qualidade nutricional e esverdeamento pós colheita de tubérculos de batata. Pesquisa Agropecuária Brasileira, vol. 46, n. 8, p. 953-960. http:// dx.doi.org/10.1590/S0100-204X2011000800023

FAO (2017) - Faostat Database Gateway 2014. Food and Agriculture Organization. [cit. 2017.01.23]. http://faostat. fao.org/site/567/default.aspx

Fernandes, A.M. (2010) - Crescimento, produtividade, acúmulo e exportação de nutrientes em cultivares de batata (Solanum tuberosum L.), 2010. 144 f. Dissertação (Mestrado) - Universidade Estadual Paulista, Faculdade de Ciências Agronômicas, Botucatu.

Fernandes, A.M.; Soratto, R.P. \& Beatrice, L.S.R. (2011) -Extração e exportação de nutrientes em cultivares de batata: I - macronutrientes. Revista Brasileira de Ciência do Solo, vol. 35, n. 6, p. 2039-2056. http://dx.doi. org $/ 10.1590 /$ S0100-06832011000600020

Fernandes, A.M.; Soratto, R.P.; Moreno, L. de A. \& Evangelista, R.M. (2015) - Qualidade de tubérculos frescos de cultivares de batata em função da nutrição fosfatada. Bragantia, vol. 74, n. 1, p.102-109. http:// dx.doi.org/10.1590/1678-4499.0330

Fernandes, A.M.; Soratto, R.P.; Evangelista, R.M. \& Nardin, I. (2010) -Qualidade físico-química e de fritura de tubérculos de cultivares de batata na safra de inverno. Horticultura Brasileira, vol. 28, n. 3, p. 299-304. http://dx.doi.org/10.1590/S0102-05362010000300010

Ferreira, D.M. (2015) - Produção e qualidade de batata cultivar Ágata sob adubação mineral e organomineral. Dissertação de Mestrado. Vitória da Conquista. Universidade Estadual do Sudoeste da Bahia, 95 p.

Furlaneto, A.; Lima, P.F.F. de S.; Daiuto, E.R.; Job, A.L.G.; Mendonça, V.Z. de; Vieites, R.L. \& Carvalho, L.R. de (2014) - Qualidade de batata cv. Ágata influenciada por diferentes concentrações de adubação potássica. Revista Iberoamericana de Tecnología Postcosecha, vol. 15, n. 2, p. 187-192.

Guigou, M.; Lareo, C.; Pérez, L.V.; Lluberas, M.E.; Vázquez, D. \& Ferrari, M.D. (2011) - Bioethanol production from sweet sorghum: evaluation of post-harvest treatments on sugar extraction and fermentation. Biomass and Bioenergy, vol. 35, n. 7, p. 3058-3062. http://dx.doi.org/10.1016/j.biombioe.2011.04.028

IBGE (2017) - Levantamento sistemático da produção agrícola. Instituto Brasileiro de Geografia e Estatística . [cit. 2014.03.16].

Instituto Adolfo Lutz. (1985) - Normas analíticas: métodos químicos e físicos para análises de alimentos. 3. ed. São Paulo, vol. 1, 533 p.

Luz, J.M.Q.; Queiroz, A.A.; Borges, M.; Oliveira, R.C.; Leite, S.S. \& Cardoso, R.R. (2013) - Influence of phosphate fertilization on phosphorus levels in foliage and tuber yield of the potato cv. Ágata. Semina: Ciências Agrárias, vol. 34, n. 2, p. 649-656. http://dx.doi.org/10.5433/1679-0359.2013v34n2p649

Martins, P.A. (2007) - Análises físico-químicas utilizadas nas empresas de vinificação necessárias ao acompanhamento do processo de elaboração de vinhos brancos. Monografia Tecnólogo em Viticultura e Enologia. Bento Gonçalves, Centro Federal de educação tecnológica de Bento Gonçalves, 49 p.

Mesquita, H.A. de (2004) - Produção, qualidade e teores de nutrientes da batata (Solanum tuberosum L.), em solos sob cerrado, em função do boro. Tese de Doutoramento. Lavras, Universidade Federal de Lavras, 96 p.

Nardin, I. (2009) - Qualidade, suscetibilidade ao esverdeamento e aptidão culinária de cultivares de batata (Solanum tuberosum L.). Especialização Monografia. Botucatu, UNESP-FCA, 96 p.

Pereira, E.A.C.; Brandão, R.P. \& Garcia, U. (2014) - Potássio em batata é o nutriente da qualidade. Revista Campo \& Negócios Hortifruti, [cit. 2017.01.20]. http://www.revistacampoenegocios.com.br/ potassio-em-batata-e-o-nutriente-da-qualidade/

Pinelli, L.L.O.; Moretti, C.L.; Almeida, G.C.; Santos, J.Z.; Onuki, A.C.A. \& Nascimento, A.B.G. (2005) Caracterização química e física de batatas Ágata minimamente processadas, embaladas sob diferentes atmosferas modificadas ativas. Pesquisa Agropecuária Brasileira, vol. 40, n. 10, p. 1035-1041. http://dx.doi. org/10.1590/50100-204X2005001000013

Públio, A.P.P.B. (2008) - Características físico-químicas de tubérculos de batata submetidos a fontes e concentrações de potássio. Dissertação de Mestrado. Vitória da Conquista, Universidade Estadual do Sudoeste da Bahia, 58 p.

Quadros, D.A. dos; Iung, M.C.; Ferreira, S.M.F. \& Freitas, R.J.S. de (2010) - Qualidade de batata para fritura, em função dos níveis de açúcares redutores e não-redutores, durante o armazenamento à temperatura ambiente. Acta Scientiarum Technology, vol. 32, n. 4, p. 439-443. http://dx.doi.org/10.4025/actascitechnol.v32i4.6663 
Robles, W.G.R. (2003) - Dióxido de carbono via fertirrigação em batateira (Solanum tuberosum L.) sob condições de campo. Tese de Doutoramento. Piracicaba, Escola Superior de Agricultura Luiz de Queiroz, 160 p.

Silva, G.O.; Pereira, A.S.; Suinaga, F.A. \& Ponijaleki, R. (2014) - Adubação nitrogenada no rendimento da cultivar de batata BRS Ana. Horticultura Brasileira, vol.32, n. 1, p. 107-110. http://dx.doi.org/10.1590/ $\underline{\text { S0102-05362014000100018 }}$

Southgate, D.A.T. (1991) - Determination of foods carbohydrates. Elsevier Applied Science, London. 232 p.

Stark, J.C.; Olsen, N.; Kleinkopf, G.E. \& Love, S.L. (2003) - Tuber quality. In: Stark, J.C. \& Love, S.L. (Eds.) Potato production systems. University of Idaho, Aberdeen, p. 329-343.

Suchoronczek, A.; Jadoski, S.O.; Botelho, R.V.; Santos, J. dos \& Camacho, A.D. (2016) - Efeito de épocas de colheita e tempo de armazenamento de tubérculos de batata sobre características de qualidade pós-colheita. Applied Research \& Agrotechnology, vol. 9, n. 1, p. 45-53. http://dx.doi.org/10.5935/PAeT.V9.N1.05

Toivonen, P.M.A. \& Brummell, D.A. (2008) - Biochemical bases of appearance and texture changes in freshcut fruit and vegetables. Postharvest Biology and Technology, vol. 48, n. 1, p. 1-14. http://dx.doi.org/10.1016/j. postharvbio.2007.09.004

Virmond, E.P.; Kawakami, J.; Voncik, K.S.; Córdova, K.R.V. \& Slompo, P.J.H. (2014) - Características físico-químicas de cultivares de batata sob cultivo orgânico. Ambiência, vol. 10, n. 1, p. 31-42. http://dx.doi. org/10.5935/ambiencia.2014.01.03

Zebarth, B.J.; Drury, C.F.; Tremblay, N. \& Cambouris, A.N. (2009) - Opportunities for improved fertilizer nitrogen management in production of arable crops in eastern Canada: A review. Canadian Journal Soil Science, vol. 89, n. 2, p. 113-132. http://dx.doi.org/10.4141/CJSS07102

Zorzella, C.A.; Vendruscolo, J.L.S.; Treptow, R.O. \& Almeida, T.L. (2003) - Caracterização física, química e sensorial de genótipos de batata processados na forma chips. Brazilian Journal of Food Technology, vol. 6, p.15-24. 